\title{
Effect of the Partial Substitution of Zn with Co, Ni, and Co-Ni on Microstructures and Mechanical Properties of Long-Period Stacking Ordered Dominant Mg-Y-Zn Alloys
}

\author{
Heng Xue, ${ }^{1,2}$ Jinbei Lyu, ${ }^{1,2}$ Fengxue Wang, ${ }^{1,2}$ Hongxin Liao, ${ }^{1,2}$ Jonghyun Kim (D), ${ }^{1,2}$ \\ and Fusheng Pan $^{1,2}$ \\ ${ }^{1}$ College of Materials Science \& Engineering, Chongqing University, Chongqing 400044, China \\ ${ }^{2}$ National Engineering Research Center for Magnesium Alloys, Chongqing University, Chongqing 40045, China \\ Correspondence should be addressed to Jonghyun Kim; joindoc@cqu.edu.cn
}

Received 23 July 2021; Accepted 13 September 2021; Published 26 October 2021

Academic Editor: Alicia E. Ares

Copyright (c) 2021 Heng Xue et al. This is an open access article distributed under the Creative Commons Attribution License, which permits unrestricted use, distribution, and reproduction in any medium, provided the original work is properly cited.

\begin{abstract}
The microstructures of $\mathrm{Mg}_{96} \mathrm{Y}_{2} \mathrm{Zn}_{2}, \mathrm{Mg}_{96} \mathrm{Y}_{2} \mathrm{Zn}_{1} \mathrm{Co}_{1}, \mathrm{Mg}_{96} \mathrm{Y}_{2} \mathrm{Zn}_{1} \mathrm{Ni}_{1}$, and $\mathrm{Mg}_{96} \mathrm{Y}_{2} \mathrm{Zn}_{1} \mathrm{Co}_{0.5} \mathrm{Ni}_{0.5}$ (at.\%) alloys were investigated by $\mathrm{XRD}, \mathrm{SEM} / \mathrm{EDS}$, and TEM. The $\alpha$-Mg matrix, the long-period stacking ordered (LPSO) phase, and the bright compounds were observed in the as-cast alloys. The ability of Co to form LPSO phase with $\mathrm{Mg}$ and $\mathrm{Y}$ is weaker than that of $\mathrm{Zn}$, but it can produce some new intermetallic compounds. The effect of Ni on phase content of alloys was opposite to that of Co. After replacing partial $\mathrm{Zn}$ with Co and $\mathrm{Ni}$, the increase in the LPSO phase is more obvious than that of Co or Ni alone to replace partial Zn. The ability to form LPSO phase with Mg and $\mathrm{Y}$ atoms in Mg-Y-TM alloys can be ranked as follows: Co-Ni $>\mathrm{Ni}>\mathrm{Zn}>\mathrm{Co}$. From the point-ofview of mechanical performance, the substitution of $\mathrm{Co}-\mathrm{Ni}$ for partial replacement of $\mathrm{Zn}$ exhibited the best yield strength; the tensile yield strength, ultimate tensile strength, compressive yield stress, and ultimate compressive stress of which were $345 \mathrm{MPa}$, $453 \mathrm{MPa}, 335 \mathrm{MPa}$, and $470 \mathrm{MPa}$, respectively. However, the ductility did not improve significantly.
\end{abstract}

\section{Introduction}

Mg-based alloys are desirable structural materials in the fields of aerospace, defense military, electronic industries, and biomedical applications for their excellent properties. These include low density, good machinability, damping capacity, high specific strength, and biodegradable and biocompatible characteristics [1-3]. However, the poor machining properties and low strength of magnesium alloys limit widespread application $[4,5]$. Therefore, improving the properties of $\mathrm{Mg}$ alloys to expand the application areas has become a research hot spot.

In recent years, long-period stacking ordered (LPSO) phases in Mg-TM-RE alloys have attracted the research interest of many researchers owing to good mechanical properties [6, 7]. Kawamura et al. [8] made a significant breakthrough and prepared $\mathrm{Mg}_{97} \mathrm{Zn}_{1} \mathrm{Y}_{2}$ (at.\%) by a rapidly solidified powder metallurgy process; the yield strength (YS) reached at $610 \mathrm{MPa}$, and the elongation reached at 5\% at room temperature. Since then, LPSO has been extensively researched owing to its unique structure. Ye et al. [9] found that hot-extruded Mg-1.5Zn-2Y-0.5Sn (at.\%) alloy exhibited an ultimate tensile strength (UTS) of $379 \mathrm{MPa}$ and hotextruded $\mathrm{Mg}-1.5 \mathrm{Zn}-2 \mathrm{Y}-1 \mathrm{Sn}$ (at.\%) exhibited an elongation of $17.6 \%$. The addition of $\mathrm{Mn}$ can improve the mechanical properties by refining grain size in $\mathrm{Mg}-\mathrm{Y}-\mathrm{Zn}$ alloys [10]. Shi et al. [11] investigated $\mathrm{Mg}_{94} \mathrm{Zn}_{3} \mathrm{Y}_{1.5} \mathrm{Gd}_{1.5}$ (mole fraction, \%) alloys, which exhibited ultimate compressive strength (UCS), compressive yield strength (CYS), and compressive plastic strain of $414 \mathrm{MPa}, 230 \mathrm{MPa}$, and $18.2 \%$.

Additionally, it has been shown that $\mathrm{Co}$ and $\mathrm{Ni}$ have important effects on the properties of magnesium alloys. Itoi et al. [12] studied ternary $\mathrm{Mg}_{90.5} \mathrm{Ni}_{3.25} \mathrm{Y}_{6.25}$ (at.\%) alloy prepared by hot-rolling and found that this alloy exhibited $\sigma_{\mathrm{y}}, \sigma_{\mathrm{UTS}}$, and $\delta$ of $460 \mathrm{MPa}, 526 \mathrm{MPa}$, and $8 \%$ at room temperature. Meanwhile, the LPSO structure observed in the 
$\mathrm{Mg}_{90.5} \mathrm{Ni}_{3.25} \mathrm{Y}_{6.25}$ (at.\%) cast alloy is $18 \mathrm{R}$ LPSO, which is consistent with the type that has been discovered in Mg-YZn alloys [13]. Gao et al. [14] found that the addition of Co to $\mathrm{Mg}-\mathrm{Y}$ alloys can form the LPSO phases and refine grain size and tensile yield strength (TYS) of the as-extruded Mg-6Y$1 \mathrm{Co}$ (at.\%) alloys reached $369 \mathrm{MPa}$. Jin et al. [15] reported that $29 \mathrm{H}, 51 \mathrm{R}, 60 \mathrm{H}, 72 \mathrm{R}, 102 \mathrm{R}$, and 192R LPSO existed in the as-cast $\mathrm{Mg}_{92} \mathrm{Y}_{6} \mathrm{Co}_{2}$ (at.\%) alloy.

However, the effect of $\mathrm{Ni}$ and $\mathrm{Co}$ in $\mathrm{Mg}-\mathrm{Y}-\mathrm{Zn}$ alloys has not been extensively studied. It is interesting and meaningful to investigate and compare the effect of $\mathrm{Ni}, \mathrm{Co}$, and $\mathrm{Co}-\mathrm{Ni}$ in $\mathrm{Mg}-\mathrm{Y}-\mathrm{Zn}$ alloy systems. Based on previous studies [12-15], we designed $\mathrm{Mg}_{96} \mathrm{Y}_{2} \mathrm{Zn}_{2}$ (MYZ), $\mathrm{Mg}_{96} \mathrm{Y}_{2} \mathrm{Zn}_{1} \mathrm{Co}_{1}$ (MYZC), $\mathrm{Mg}_{96} \mathrm{Y}_{2} \mathrm{Zn}_{1} \mathrm{Ni}_{1}$ (MYZN), and $\mathrm{Mg}_{96} \mathrm{Y}_{2} \mathrm{Zn}_{1} \mathrm{Co}_{0.5} \mathrm{Ni}_{0.5}$ (MYZCN) (at.\%) alloys and systematically investigated the microstructure evolution and mechanical performance.

\section{Experiment}

2.1. Material Preparation. The investigated alloys composed of MYZ, MYZC, MYZN, and MYZCN were prepared from commercial pure $\mathrm{Mg}(>99.99 \%)$ and pure $\mathrm{Zn}(>99.8 \%)$, and Mg-Y (30 wt.\%), Mg-Co (16 wt.\%), and Mg-Ni (25 wt.\%) master alloys by induction melting in an electric resistance furnace under an atmosphere of a mixture of $\mathrm{CO}_{2}$ and $\mathrm{SF}_{6}$. The melt was poured into steel mold to produce ingots with dimensions of $\varphi 80 \mathrm{~mm} \times 200 \mathrm{~mm}$ and then cooled to room temperature. The ingots were given a homogenization treatment for $500^{\circ} \mathrm{C}$ for $24 \mathrm{~h}$ and then quenched in water. The extrusion was carried out at $430^{\circ} \mathrm{C}$ with a ram speed of $1 \mathrm{~mm} / \mathrm{s}$ and an extrusion ratio of $11: 1$.

\subsection{Microstructure Characterization and Mechanical Tests.} The chemical compositions of as-cast MYZ, MYZC, MYZN, and MYZCN alloys were measured by an XRF-1800 sequential X-ray fluorescence spectrometer and are shown in Table 1. The constituent phases of the as-cast alloys were identified using X-ray diffraction (XRD). A scanning electron microscope (SEM) equipped with energy dispersive spectrometry (EDS) and an HKL channel 5 electron backscattered diffraction unit (EBSD), backscattered electron spectrometry (BSE), and transmission electron microscopy (TEM) were used to describe the microstructures and phase morphologies of the experiment alloys. The tensile and compressive tests were performed on a CMT5105 material testing machine at a strain rate of $1.5 \times 10^{-3} \mathrm{~s}^{-1}$ at room temperature. Each test was repeated three times for each sample. The tensile tests were along the extrusion direction (ED), and the diameter and gauge length of the specimens were $6 \mathrm{~mm}$ and $36 \mathrm{~mm}$, respectively. The compressed samples size is $\varphi 12 \mathrm{~mm} \times 8 \mathrm{~mm}$.

\section{Results}

3.1. Microstructure. Figure 1 shows the backscattered electron (BSE) images of microstructures of the as-cast alloys. Three different phases are observed in these four alloys: the black phase, the grey phase, and the bright phase. According to the EDS analysis, the black phases are mainly composed of
Table 1: . Chemical composition (at.\%) of experimental alloys.

\begin{tabular}{lcccccc}
\hline Alloys & & Y & Zn & Co & $\mathrm{Ni}$ & $\mathrm{Mg}$ \\
\hline \multirow{2}{*}{ MYZ } & Design & 2.00 & 2.00 & - & - & Bal. \\
& Actual & 2.04 & 2.03 & - & - & Bal. \\
\multirow{2}{*}{ MYZC } & Design & 2.00 & 1.00 & 1.00 & - & Bal. \\
& Actual & 2.02 & 0.94 & 0.94 & - & Bal. \\
\multirow{2}{*}{ MYZN } & Design & 2.00 & 1.00 & - & 1.00 & Bal. \\
& Actual & 1.83 & 1.00 & - & 1.04 & Bal. \\
\multirow{2}{*}{ MYZCN } & Design & 2.00 & 1.00 & 0.50 & 0.50 & Bal. \\
& Actual & 1.78 & 0.95 & 0.49 & 0.55 & Bal. \\
\hline
\end{tabular}

Mg element, which is identified as $\alpha-\mathrm{Mg}$ matrix (solid solution). In Mg-Y-Zn ternary alloys, Mg12YZn is the LPSO phase. The EDS results of the grey phases show that the value of $\mathrm{Mg}:(\mathrm{Zn}, \mathrm{Co}, \mathrm{Ni})$ is close to $12: 1$, indicating that the grey phases are LPSO phases. The bright phases are some small white particles (blue arrows), which are detected as some intermetallic compounds. Furthermore, there are some phases that exhibit network structures (red arrows) in MYZN and MYZCN alloys, which are considered as eutectic structure, distributing between the black phases and the grey phases [16].

Figure 2 presents the XRD patterns of as-cast alloys to identify the phase composition. The distribution of diffraction peaks does not change too much with the change of the alloy elements. All four alloys are mainly composed of the $\alpha-\mathrm{Mg}$ and the LPSO phase. Table 2 summarizes the chemical composition of the LPSO phases in the four alloys (as shown by the white arrows in Figure 1), indicating that the LPSO phases are, respectively, $\mathrm{Mg}_{12} \mathrm{YZn}, \mathrm{Mg}_{12} \mathrm{Y}(\mathrm{Zn}$, $\mathrm{Co}), \mathrm{Mg}_{12} \mathrm{Y}(\mathrm{Zn}, \mathrm{Ni})$, and $\mathrm{Mg}_{12} \mathrm{Y}(\mathrm{Zn}, \mathrm{Co})+\operatorname{Mg} 12 \mathrm{Y}$ (Zn, Ni) in MYZ, MYZC, MYZN, and MYZCN alloys. In addition, some weak diffraction peaks are proved to be $\mathrm{Mg}_{24} \mathrm{Y}_{5}$, $\mathrm{Mg}_{2} \mathrm{Ni}$, and $\mathrm{MgYCo}_{4}$, which are compounds in the alloys.

The BSE images of as-homogenized alloys are shown in Figure 3. After heat treatment at $500^{\circ} \mathrm{C}$ for $24 \mathrm{~h}$, some eutectic phases dissolved into the $\alpha-\mathrm{Mg}$ matrix and the matrix phases became larger in size. However, there was little change in the morphology of each phase. Figure 4 shows the BSE images of extruded alloys. After extrusion at $430^{\circ} \mathrm{C}$, the morphology of phases changed from bulk-shaped phases to strip-shaped phases, and the deformation direction is along the extrusion direction (ED). Compared with the alloy without $\mathrm{Ni}$, the matrix size of the Ni-containing MYZN and MYZCN alloys becomes smaller, and the large block matrix phase almost disappeared.

The volume fraction of each phase in the as-cast and extruded alloys is shown in Table 3. The volume fractions of the LPSO phase in the MYZ, MYZC, MYZN, and MYZCN as-cast and extruded alloys are $32.8 \%, 31.5 \%, 34.2 \%$, and $37.3 \%$ and $33.7 \%, 31.9 \%, 39.8 \%$, and $43.6 \%$, respectively. The replacement of partial $\mathrm{Zn}$ with Co reduced the content of the LPSO phase, but the replacement of partial $\mathrm{Zn}$ with $\mathrm{Ni}$ increased the amount of LPSO phase. The amount of the compounds increased when Co existed in the alloy, which is consistent with the BSE images. After heat treatment for $500^{\circ} \mathrm{C} \times 24 \mathrm{~h}$ and extrusion at $430^{\circ} \mathrm{C}$, the LPSO phase 

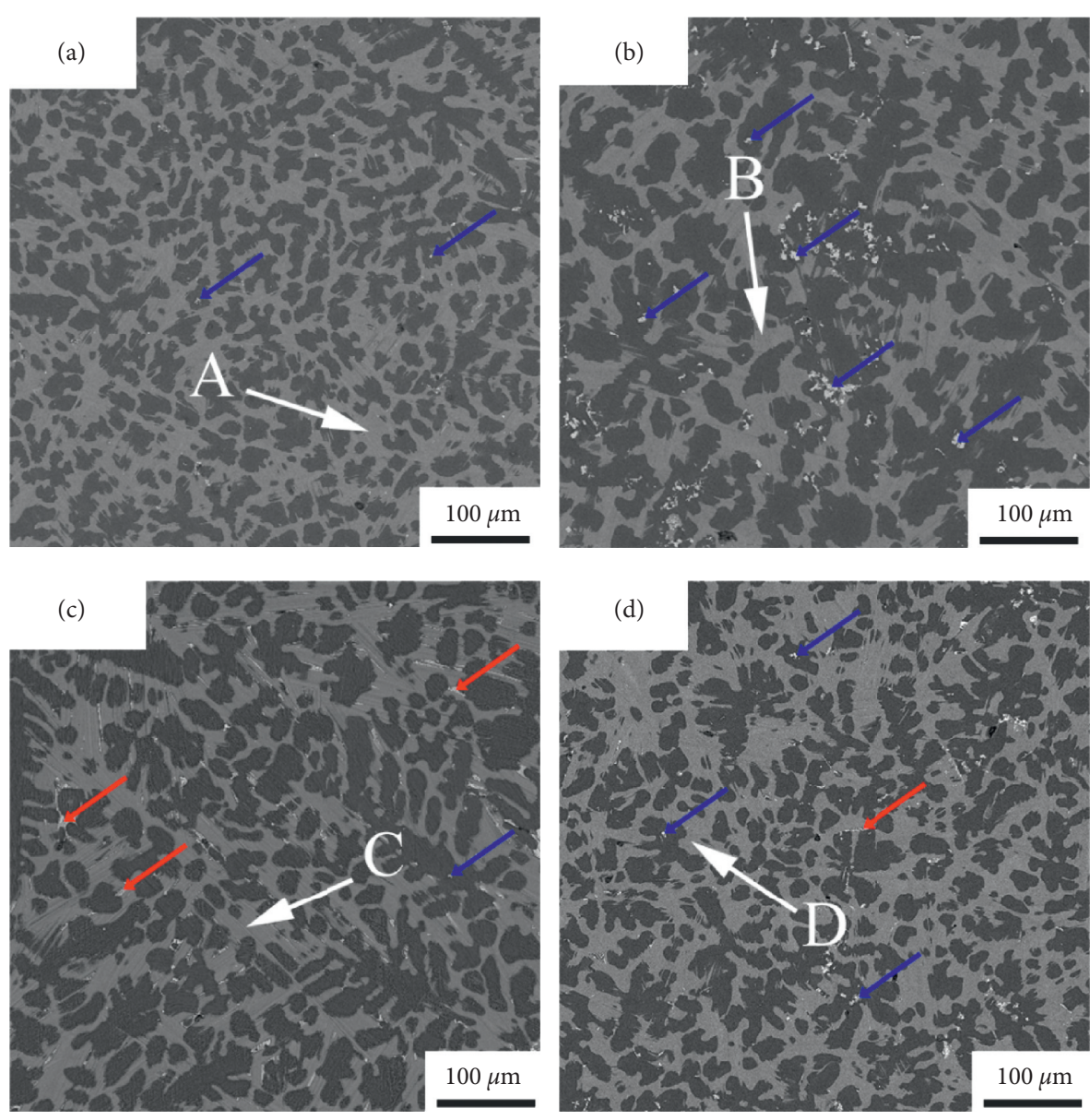

Figure 1: BSE images of as-cast (a) MYZ, (b) MYZC, (c) MYZN, and (d) MYZCN alloys.

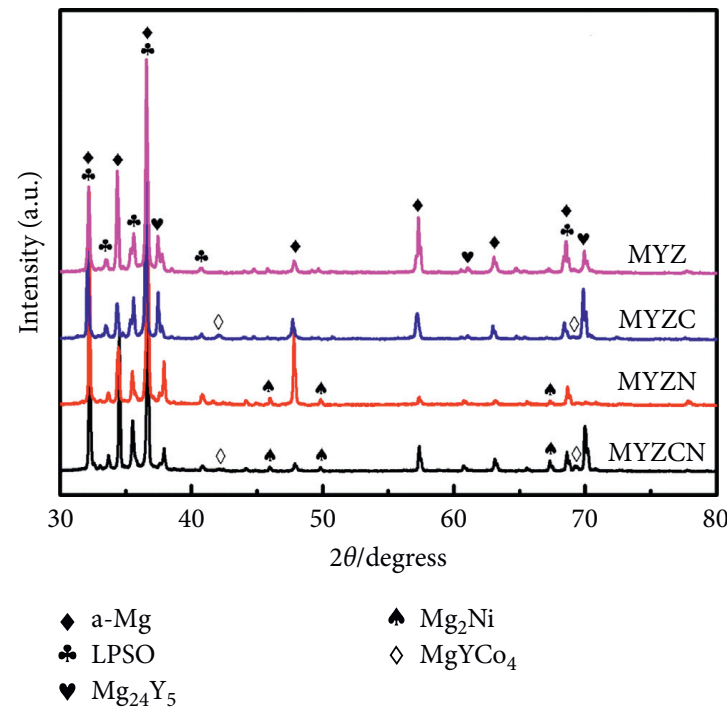

Figure 2: XRD patterns of as-cast MYZ, MYZC, MYZN, and MYZCN alloys.

increased. Especially, when elemental Ni was added (as in the case of the MYZN and MYZCN alloys), the increment was noticeable.
Figure 5 shows the TEM bright field images and the corresponding selected area electron diffraction (SAED) patterns of four alloys. As can be seen from the figures, the 
TABLE 2: EDS elemental analysis of the phases marked in Figure 1.

\begin{tabular}{lccccc}
\hline \multirow{2}{*}{ Point } & & \multicolumn{3}{c}{ Composition (at.\%) } \\
\\
\hline A & Mg & Y & Zn & Co & Ni \\
B & 87.16 & 6.87 & 5.97 & - & - \\
C & 88.35 & 6.34 & 2.79 & 2.52 & - \\
D & 87.62 & 6.76 & 2.85 & 1.88 & 2.77 \\
\hline
\end{tabular}
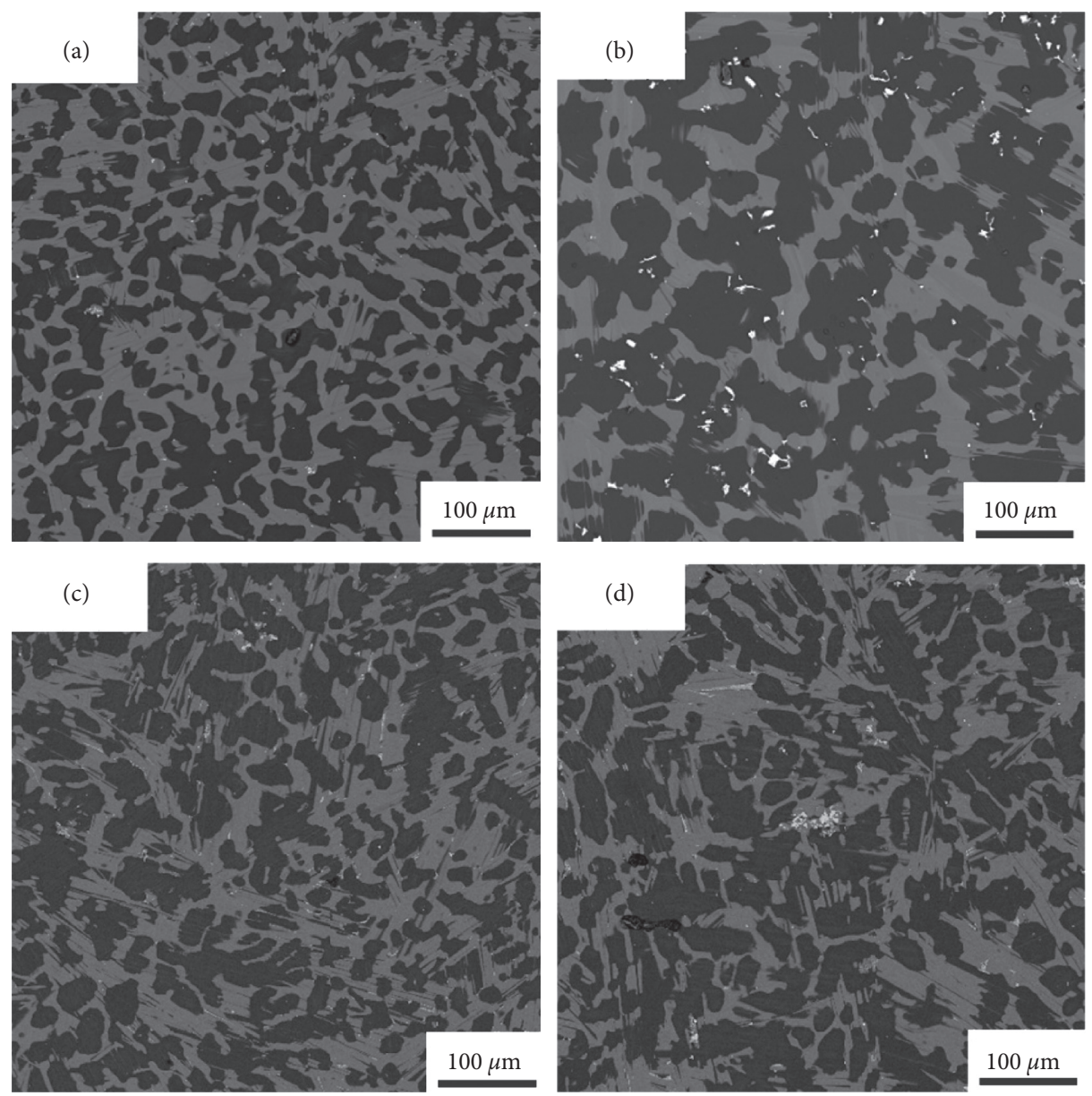

Figure 3: BSE images of as-homogenized (a) MYZ, (b) MYZC, (c) MYZN, and (d) MYZCN alloys.

LPSO phases present two morphologies: bulk-shaped phase and lamellar phase. According to the SAED patterns of the LPSO structure, there are 7 weak diffraction spots appearing at positions of $n / 7$ (where $n$ is an integer) of the $(0002)_{\mathrm{Mg}}$ diffraction, indicating that two forms of LPSO phases in these alloys are both $14 \mathrm{H}$ type. This result is consistent with the previous literature [17]. Co and Ni have no effect on the structure of LPSO phase in these alloys.

Figure 6 shows the mechanical properties of the extruded alloys at room temperature in tensile and compressive condition. Obviously, the substitution of $\mathrm{Co}$ and $\mathrm{Ni}$ for partial $\mathrm{Zn}$ has a great influence on the mechanical properties. The tensile yield strength (TYS), ultimate tensile strength (UTS), compressive yield strength (CYS), and ultimate compressive strength (UCS) of the extruded alloys decreased when replaced with Co. On the contrary, the extruded alloys exhibited higher values in TYS, UTS, CYS, and UCS with the partial substitution of Ni. The partial substitution of Co-Ni shows the highest strength, but it has an adverse effect on the elongation $(\varepsilon)$.

The inverse pole figure (IPF) of the extruded alloys is shown in Figure 7. Different colors indicate different grain orientation, and the same color represents the same or similar orientation. The black region corresponds to the nonindexed region, which represents the LPSO phase. The black line in the figure indicates that the angle between grain orientation is greater than $15^{\circ}$, which we define as grain boundary. The grains of the four alloys were obviously refined and most of the grains were equiaxed, indicating that dynamic recrystallization has occurred. In addition, there 

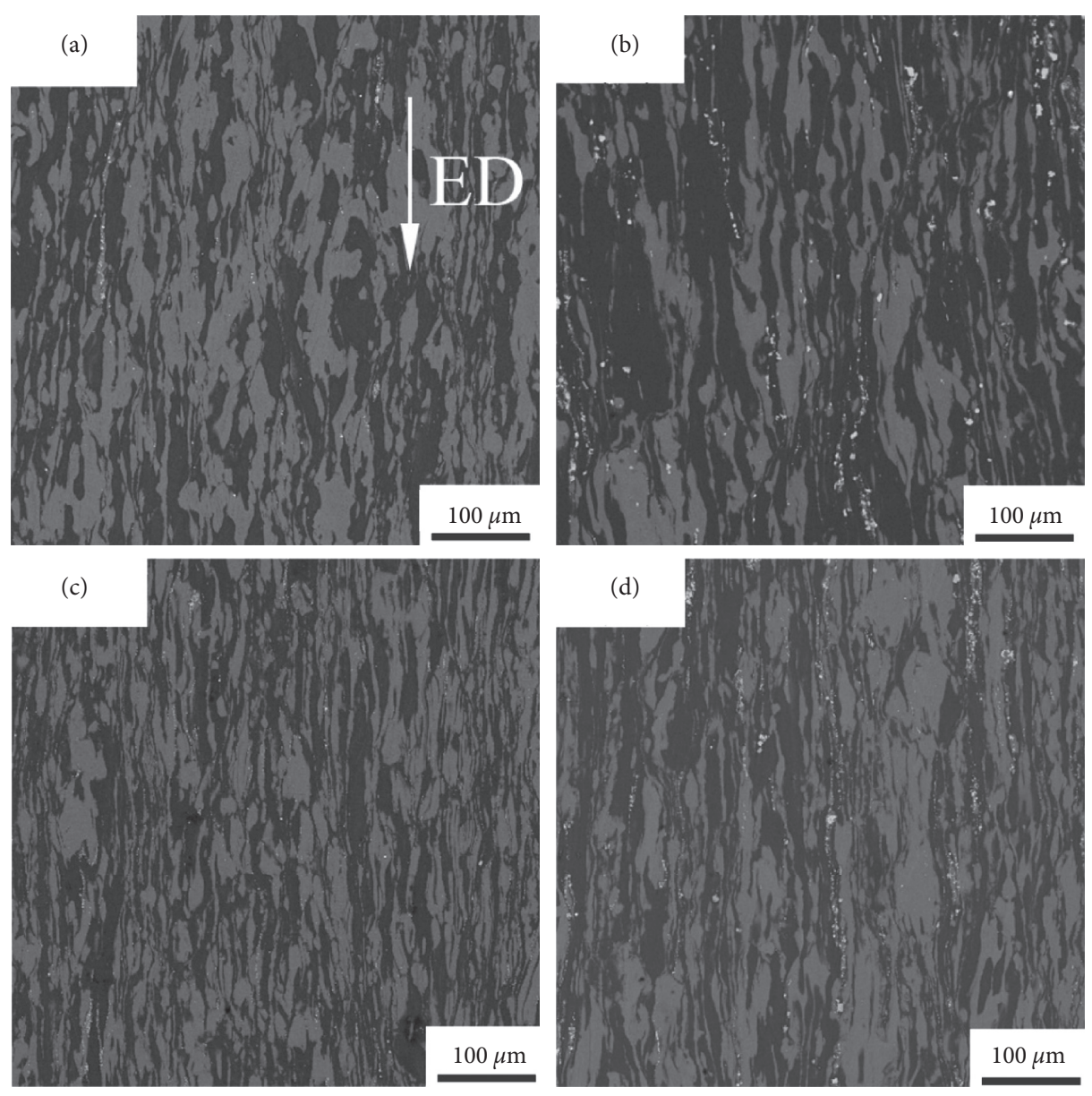

FIgURE 4: BSE images of extruded (a) MYZ,

(b) MYZC, (c) MYZN, and (d) MYZCN alloys.

TABLE 3: Volume fraction of each phase in the four alloys.

\begin{tabular}{lcccc}
\hline State & Alloys & a-Mg & LPSO & Compounds \\
\hline \multirow{4}{*}{ As-cast } & MYZ & 66.5 & 32.8 & 0.7 \\
& MYZC & 63.7 & 31.5 & 4.8 \\
& MYZN & 64.2 & 34.2 & 1.6 \\
& MYZCN & 60.4 & 37.3 & 2.3 \\
\hline \multirow{4}{*}{ Extruded } & MYZ & 65.1 & 33.7 & 1.2 \\
& MYZC & 63.6 & 31.9 & 4.5 \\
& MYZN & 59.1 & 39.8 & 1.1 \\
& MYZCN & 53.8 & 43.6 & 2.6 \\
\hline
\end{tabular}

are some larger grains. Some of these grains are undeformed grains during the extrusion process, and some are abnormally grown grains (as seen from Figure 8). The abnormal growth of the grains is due to the uneven distribution during extrusion, which hinders the growth of some grains and creates conditions for the growth of other grains. Figure 9 clearly reveals a typical fiber texture of extrusion rods with $\{0001\}$ basal plane parallel to ED. The maximum texture intensities of the MYZ, MYZC, MYZN, and MYZCN extruded alloys were 4.09, 3.23, 4.65, and 2.98 MRD (multiple random distribution), respectively. The partial substitution of $\mathrm{Zn}$ with Co decreases the texture intensity, but $\mathrm{Ni}$ increases the texture intensity.

\section{Discussions}

As shown in the BSE and XRD figures, there are some eutectic structures in the alloys. The existence of eutectic structure is harmful to the strength of the alloys because it destroys the structural integrity of the LPSO phase. During the tensile process, cracks are easily generated at the interface between the LPSO phase and the eutectic structure. With the increase in stress, the cracks will continue to extend along the direction of the eutectic structure. When they reach the $\alpha-\mathrm{Mg}$ matrix, the matrix will be split and the alloy will fracture. The main reasons for the formation of eutectic structure are as follows: due to the large difference in solid solubility (the solid solubility of $\mathrm{Ni}$ in $\mathrm{Mg}$ is close to 0 , but the maximum solid solubility of $\mathrm{Y}$ in $\mathrm{Mg}$ is 3.6 at.\%), more $\mathrm{Ni}$ atoms are discharged from the primary $\alpha-\mathrm{Mg}$ matrix than $\mathrm{Y}$ atoms, which makes the $\mathrm{Ni}$ and $\mathrm{Y}$ ratio increase continuously and gradually exceed the atomic proportion required for the formation of LPSO phase. Therefore, when the temperature is lowered to the eutectic reaction temperature, excessive $\mathrm{Ni}$ atoms participate in the eutectic reaction and form the eutectic structure $[18,19]$. The reaction equation is as follows:

$$
\mathrm{L} \longrightarrow \alpha-\mathrm{Mg}+\mathrm{LPSO}+\mathrm{Mg}_{2} \mathrm{Ni}
$$



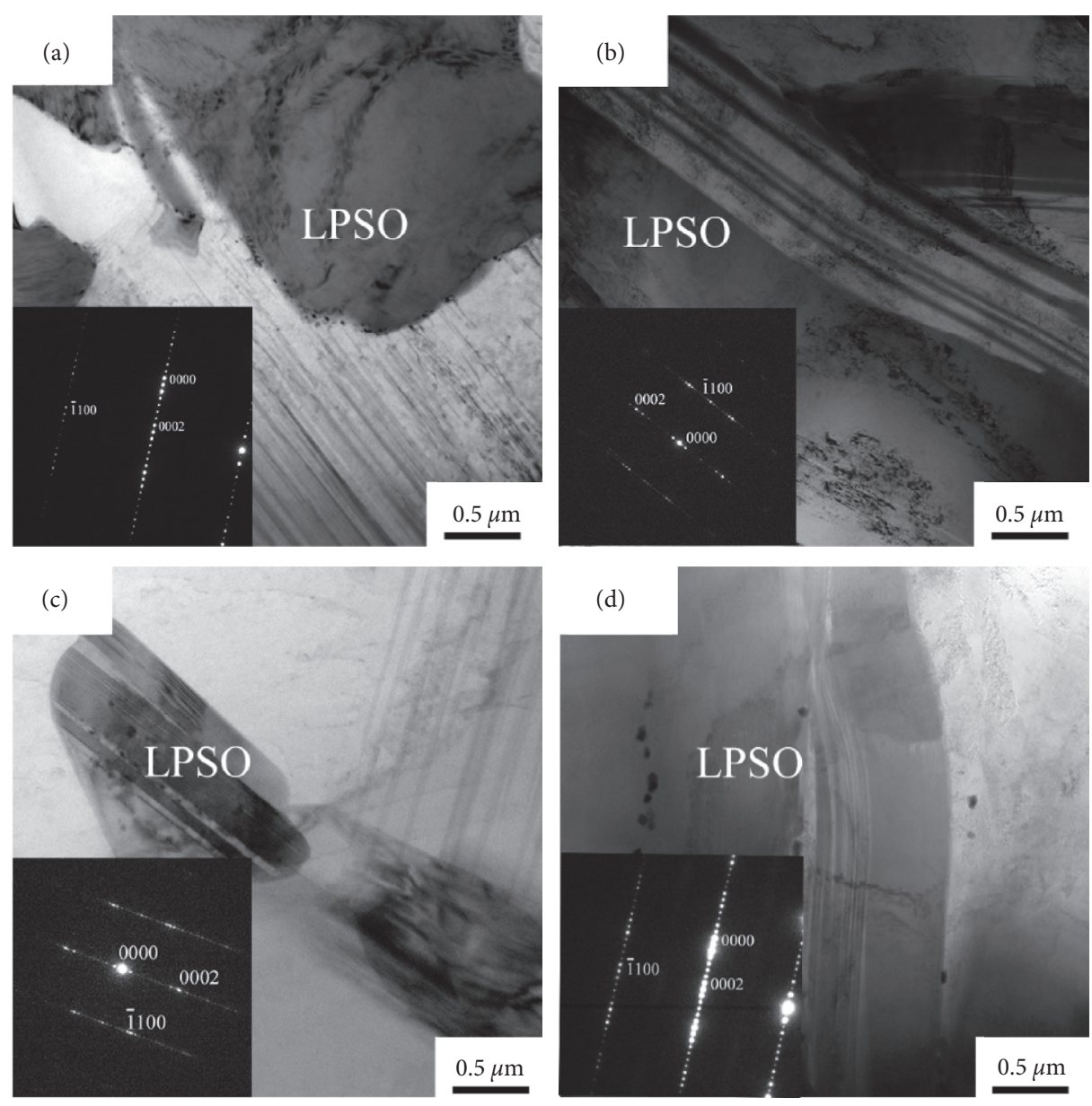

(d)

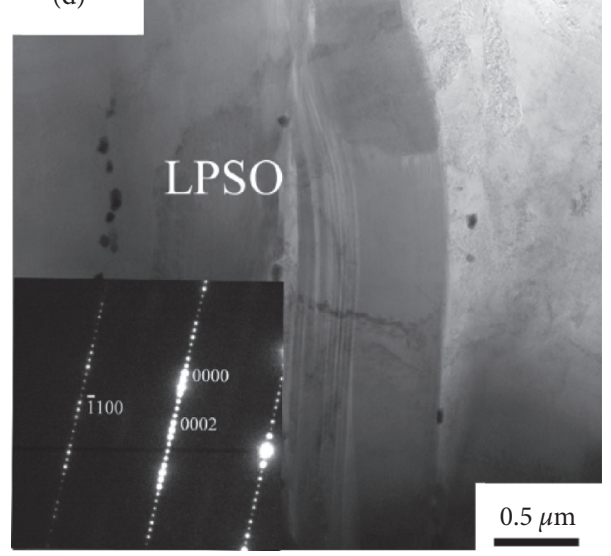

FIGURE 5: TEM bright field images and the corresponding SAED patterns of (a) MYZ, (b) MYZC, (c) MYZN, and (d) MYZCN alloys.

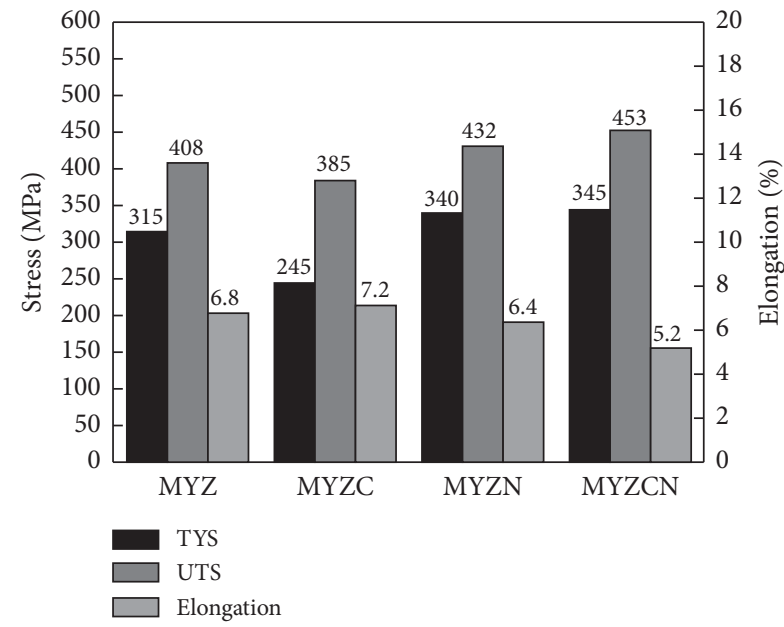

(a)

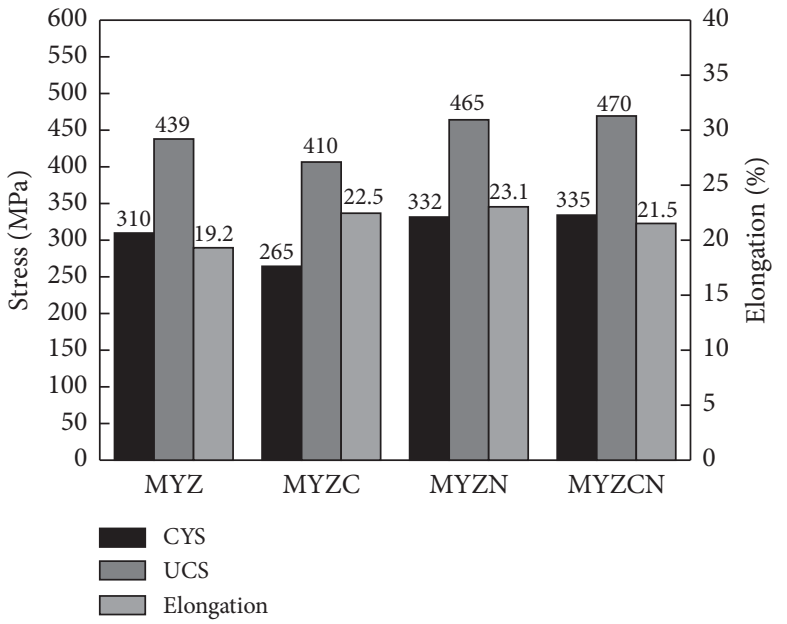

(b)

FIGURE 6: Mechanical properties of the extruded alloys.

In Mg-RE-TM alloys, the LPSO phase is the main second phase. It is currently believed that the formation of LPSO phase is caused by the precipitation of supersaturated $\alpha-\mathrm{Mg}$ solid solution, and its formation requires RE/TM elements to reach a certain ratio. The formation and growth of the
LPSO phase are mainly achieved through the following two processes: (1) stacking faults are generated through the hexagonal close packed (hcp) structure of $\mathrm{Mg}$, and the solid solution atoms in the alloy fill the stacking fault layers; (2) lattice distortion provides driving force, which promotes the 

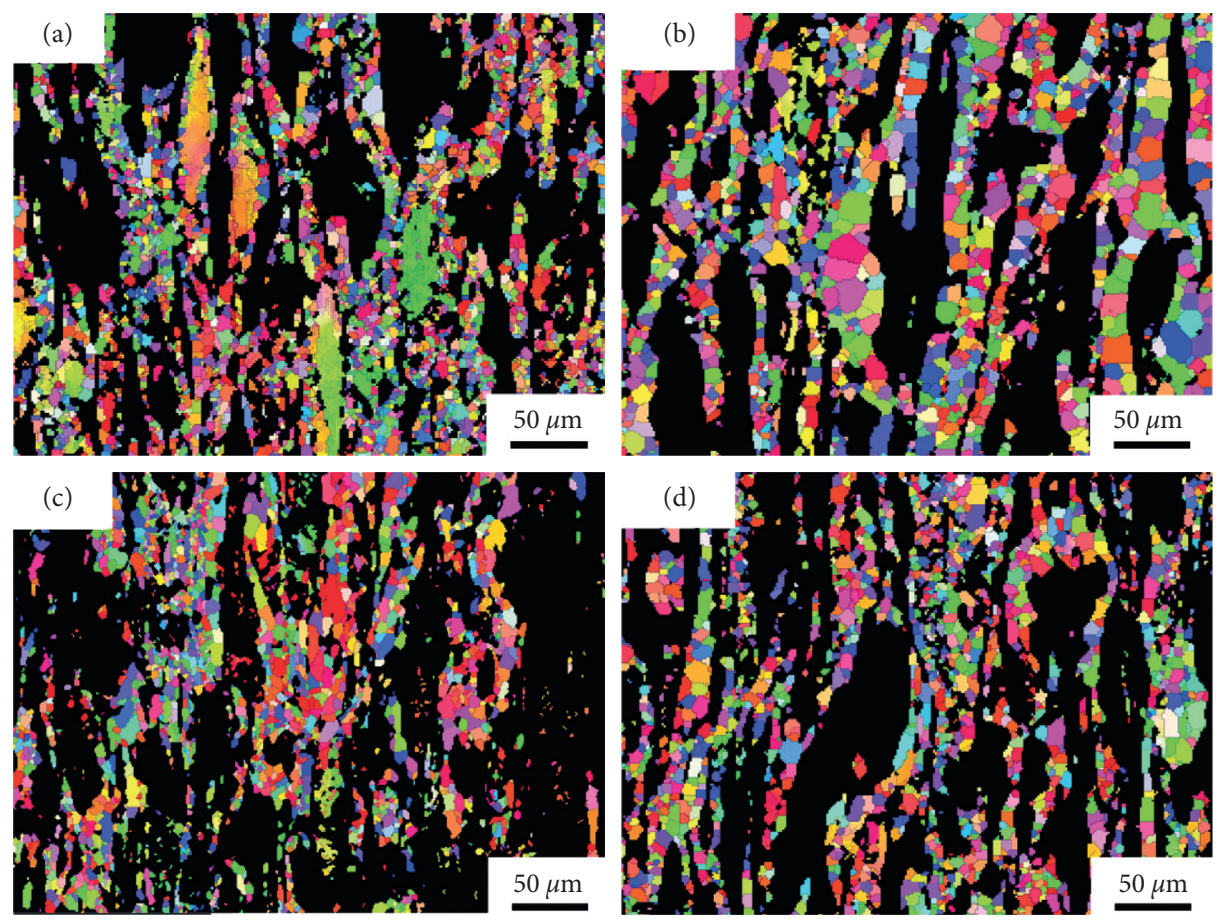

Figure 7: IPF maps of (a) MYZ, (b) MYZC, (c) MYZN, and (d) MYZCN extruded alloys.
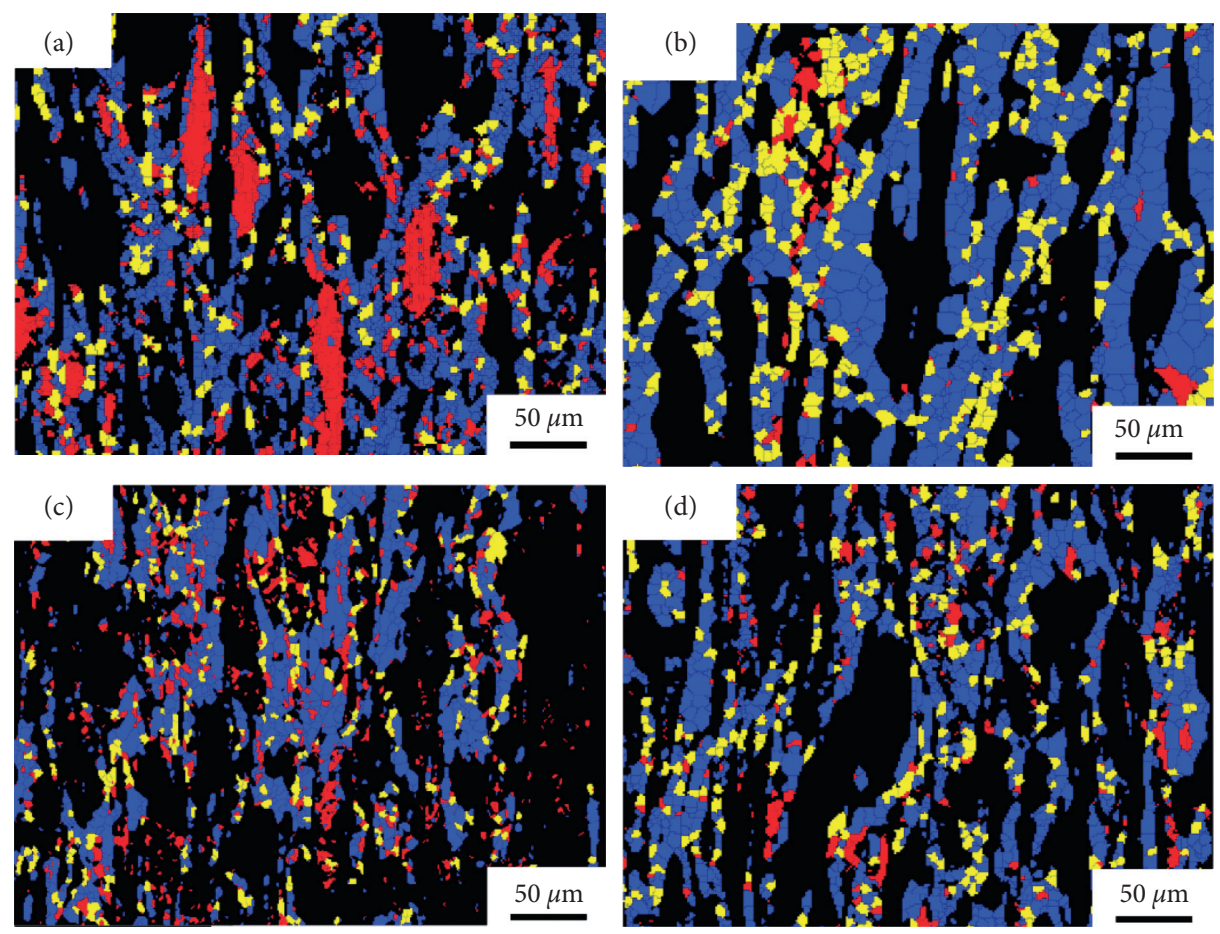

Figure 8: Different types of grains of (a) MYZ, (b) MYZC, (c) MYZN, and (d) MYZCN extruded alloys.

diffusion of solid solution atoms and then promotes the nucleation and growth of long-period structures [20]. In this work, it can be observed that the bulk LPSO phase and the lamellar LPSO phase in extruded alloys (Figure 5) are both $14 \mathrm{H}$-type LPSO phase. The lamellar $14 \mathrm{H}$ phase is precipitated from $\alpha-\mathrm{Mg}$ matrix during the heat treatment $[21,22]$. While the structure of the bulk LPSO phase is different from the 18R-type in the as-cast alloys [13], which is due to the fact that when the temperature is over $500^{\circ} \mathrm{C}$, the $18 \mathrm{R}$ structure will be transformed into $14 \mathrm{H}$ structure [23, 24]. Most studies show that higher temperature and longer heating time can greatly increase the volume fraction of the $14 \mathrm{H}$ phase [25]. 

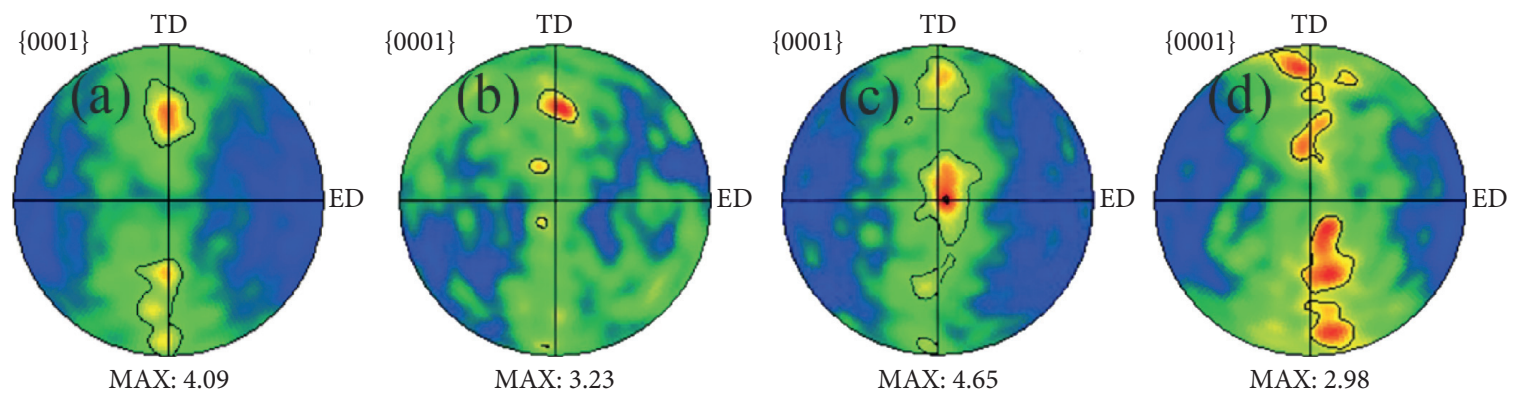

Figure 9: Pole figures of (a) MYZ, (b) MYZC, (c) MYZN, and (d) MYZCN extruded alloys.

As shown in the bright field images of the alloys (Figure 5), the contrast of the LPSO phase is darker than that of $\alpha-\mathrm{Mg}$ matrix because there are more solute atoms (such as $\mathrm{Y}$, $\mathrm{Zn}, \mathrm{Co}$, and $\mathrm{Ni}$ ) than $\mathrm{Mg}$ in the LPSO phase. From the volume fraction of each phase in Table 3 , it can be seen that when Co replaced partial $\mathrm{Zn}$, the volume fraction of the LPSO phase decreased. This is contrary to the situation in the $\mathrm{Ni}$-containing alloys. Because the mixing enthalpy of $\mathrm{Mg}$ and $\mathrm{Y}$ is $-6 \mathrm{~kJ} / \mathrm{mol}$, and $\mathrm{Mg}$ and $\mathrm{Co}$ is $3 \mathrm{~kJ} / \mathrm{mol}$, but the mixing enthalpy of $\mathrm{Co}$ and $\mathrm{Y}$ is $-22 \mathrm{~kJ} / \mathrm{mol}$, the Co atoms are more inclined to react with $\mathrm{Y}$ atoms first [14]. Combined with the XRD analysis in Figure 2 and the literature [26], we can surmise that Co atoms are mainly present in intermetallic compounds and the $\mathrm{Co} / \mathrm{Y}$ ratio of compounds is much larger than that of the LPSO phase. Therefore, Co atoms need to firstly form compounds with $\mathrm{Mg}$ and $\mathrm{Y}$ atoms to consume more Co atoms, which reduces to a suitable ratio of Co and Y to form LPSO phase. This is the reason why the LPSO phase was reduced after adding Co. The reason why $\mathrm{Ni}$ increases the volume fraction of LPSO phase is that the solid solubility of $\mathrm{Ni}$ in $\mathrm{Mg}$ is much lower than that of $\mathrm{Zn}$. Hence, compared with $\mathrm{Zn}, \mathrm{Ni}$ atoms are more difficult to be consumed by $\alpha$-Mg matrix, and more $\mathrm{Ni}$ atoms are involved in the formation of LPSO phase [16]. Therefore, the amount of the LPSO phase in MYZN and MYZCN alloys is more than that in MYZ and MYZC alloys. Specifically, the volume fraction of the LPSO phase in the Co-Ni composite addition alloys is close to $50 \%$ after extrusion. In our point-of-view, the reason for the highest volume fraction of the LPSO phase in the MYZCN alloy may be attributed to the existence of two LPSO phases: $\mathrm{Mg}_{12} \mathrm{Y}(\mathrm{Zn}, \mathrm{Co})$ and $\mathrm{Mg}_{12} \mathrm{Y}(\mathrm{Zn}, \mathrm{Ni})$. However, we still need to conduct more in-depth research on this. On the other hand, the strength of the alloys is ranked as follows (Figure 6): MYZC $<$ MYZ $<$ MYZN $<$ MYZCN, which is same as the ranking of the volume fraction of the LPSO phase in these four alloys. It can be seen that LPSO has made great contribution to the improvement of strength.

According to literature studies $[27,28]$, the strengthening of LPSO phase is the result of the combination of multiple mechanisms, but it is mainly its own strengthening. On the one hand, it is similar to the strengthening effect of the cementite in pearlite. After deformation, the LPSO phases are arranged into fibers along the extrusion direction, and these LPSO phases maintain a coherent or semicoherent relationship with each interface of $\alpha$-Mg matrix, which makes the interface strength of the two phases higher. The higher interface strength is beneficial to the increase in alloy strength. On the other hand, the strength and hardness of LPSO structure are higher than those of $\alpha$-Mg matrix. The stress required by shear deformation through LPSO structure is obviously higher than that required by $\alpha-\mathrm{Mg}$ matrix, so the existence of LPSO structure is conducive to hinder the deformation process and improve the strength of the alloy. In addition, it is also found that some LPSO phases are bent, which is due to the kink deformation to a certain extent in order to adapt to the compressive strain. The kink bands are formed by progressive rotation of the lattice via avalanche generation of pairs of dislocations on the basal plane [29]. Figure 10 shows the formation mechanism of deformed kink band [30]. Kink bands can effectively prevent dislocation movement and basal slip, which is called kink strengthening. Kink strengthening is also an important part of the LPSO strengthening mechanism.

Expecting that the second phase (LPSO phase) has a strengthening effect in the alloys, the grain size also has a great influence on the strength of the alloy. According to the Hall-Petch relationship: $\sigma_{y}=\sigma_{0}+K d^{-1 / 2}$, the smaller the grain size, the greater the yield strength of the alloy. For one thing, extrusion can severely deform large grains and break them into small grains. For the other thing, extrusion will cause the compounds to precipitate out and become dynamic recrystallization nucleation sites. The LPSO phase can also provide favorable nucleation sites for dynamic recrystallization, which can greatly promote grain refinement. Through the analysis of the EBSD data (Figure 7), the grain sizes of the alloy are, respectively: $2.8 \mu \mathrm{m}, 3.7 \mu \mathrm{m}, 2.6 \mu \mathrm{m}$, and $3.1 \mu \mathrm{m}$. Ni has a better effect on grain refinement, and the addition of Co increases the grain size, which is also one of the reasons for the lowest yield strength of MYZC alloy. Although the existence of the LPSO phase has a certain effect on grain refinement, it can be seen from Figure 6 that as the LPSO phase increased, the plasticity of the alloy decreased. Because the LPSO phase is not easy to coordinate the plastic deformation of the grains and the second phase. The deformation of the alloy can easily lead to uneven stress distribution and local stress concentration, which induces the premature initiation of microcracks, thereby deteriorating the plasticity of the alloy.

In order to further study the effect of replacing $\mathrm{Zn}$ with $\mathrm{Co}$ and $\mathrm{Ni}$ on the dynamic recrystallization behavior of the alloy, we summarized the volume fraction of recrystallized 

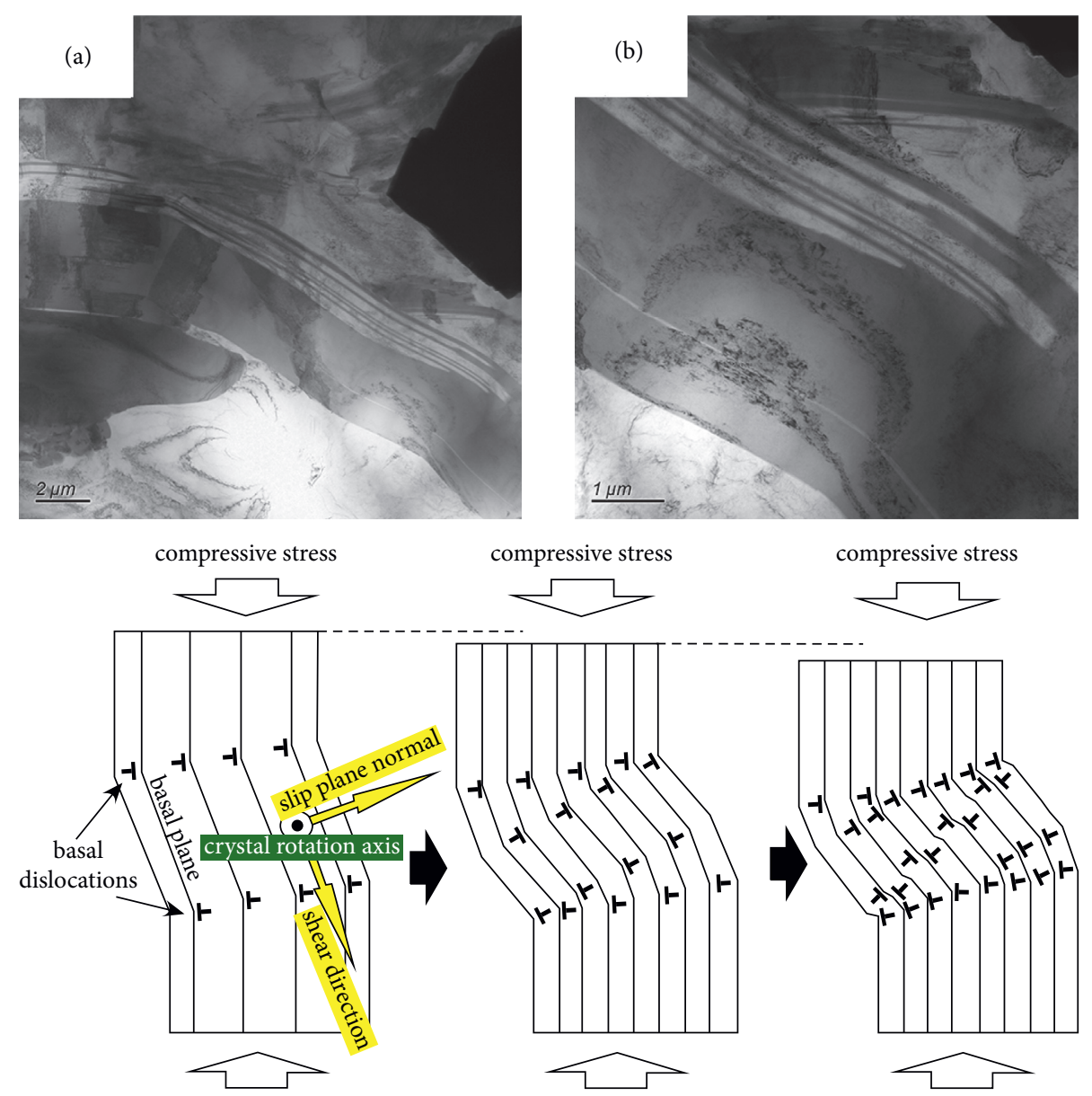

(c)

FIgUre 10: (a, b) The kink bands of LPSO phases in the extruded alloys. (c) The formation mechanism of deformed kink band [30].

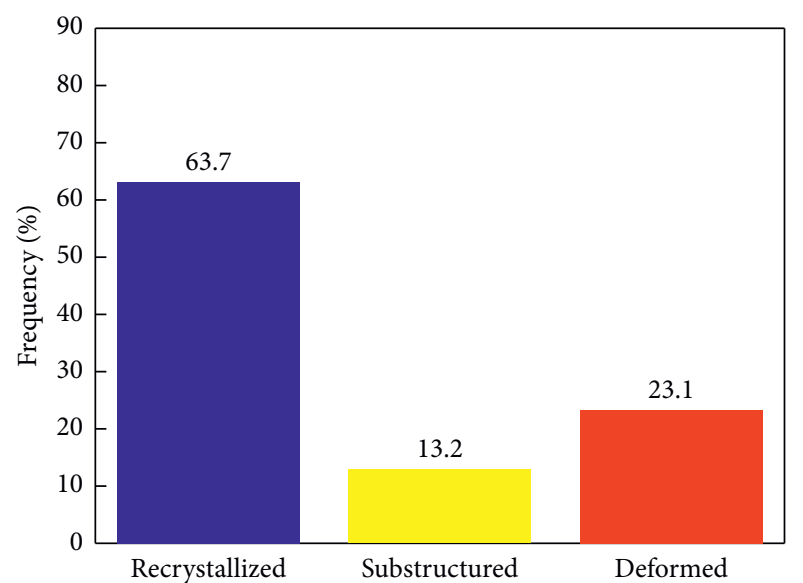

(a)

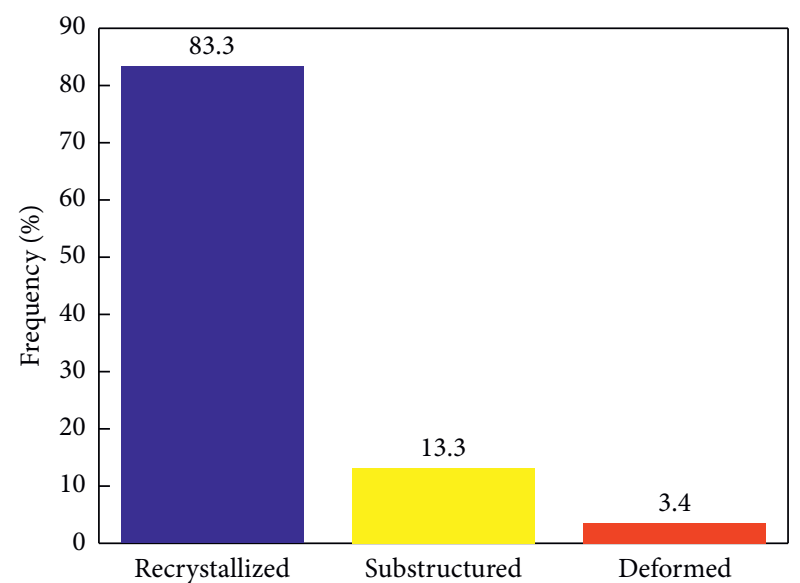

(b)

Figure 11: Continued. 


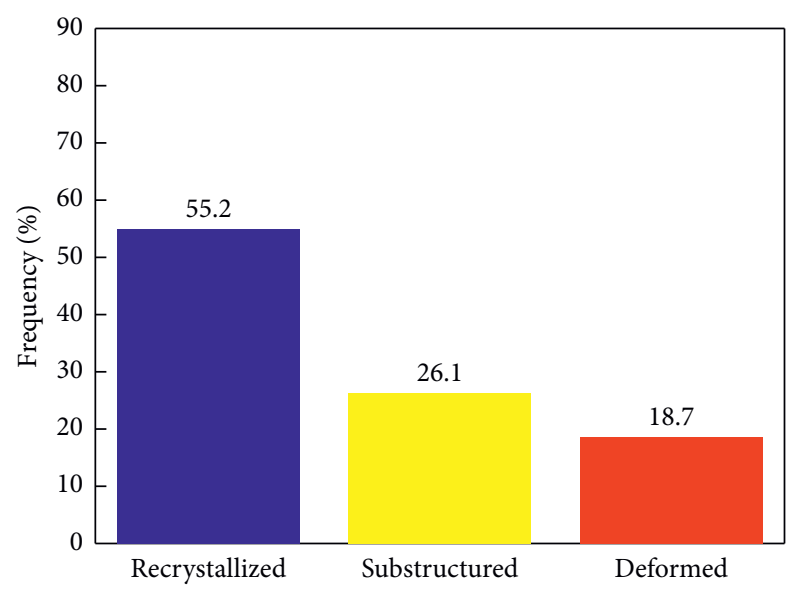

(c)

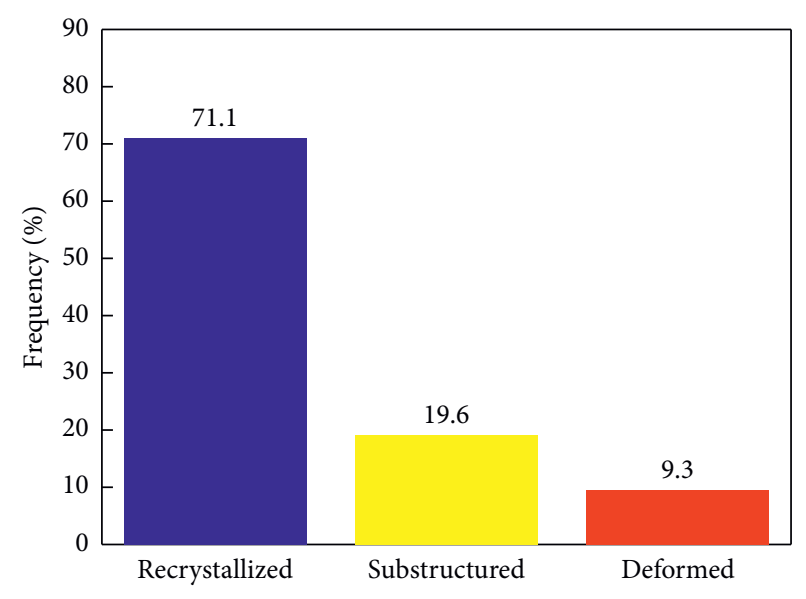

(d)

Figure 11: Frequencies of different types of grains of (a) MYZ, (b) MYZC, (c) MYZN, and (d) MYZCN extruded alloys.

grains, substructured grains, and deformed grains in the extruded MYZ, MYZC, MYZN, and MYZCN alloys from the EBSD diagram (shown in Figures 9 and 11). It can be clearly seen that after the MYZ alloy is extruded, small recrystallized grains and large deformed grains coexist, while after replacing $\mathrm{Zn}$ with $\mathrm{Co}$ and $\mathrm{Ni}$, the large deformed grains are greatly reduced. In addition, the substitution of Co greatly increases the recrystallization fraction, while $\mathrm{Ni}$ actually reduces the recrystallization fraction. Because a large number of LPSO phases will inhibit the slip of the basal surface and the recrystallization, which resulted in the lower volume fraction of recrystallized grains. This is consistent with the change rule of the LPSO phase volume fraction in the four alloys shown in Table 3.

From the above discussion, in the MYZ alloy, replacing $\mathrm{Zn}$ with Co will reduce the volume fraction of the LPSO phase, weaken the effect of grain refinement, and promote the formation of recrystallized grains. When $\mathrm{Ni}$ is used to replace $\mathrm{Zn}$, the grain size decreases and the LPSO volume fraction increases. Co and Ni compounded to replace Zn, the LPSO phase reached the maximum volume fraction of $43.6 \%$, and the strength was also significantly improved. Compared with the grain size, recrystallization, and texture, LPSO plays the most important role in strengthening the alloy.

\section{Conclusions}

(1) MYZ, MYZC, MYZN, and MYZCN alloys were all mainly composed of $\alpha$-Mg matrix, LPSO phases, and intermetallic compounds. The partial substitution of $\mathrm{Zn}$ with Co caused a sharp decrease in the volume fraction of LPSO phases. Moreover, the substitution of partial $\mathrm{Zn}$ by $\mathrm{Ni}$ increased the volume fraction of LPSO phase. When partial $\mathrm{Zn}$ atoms were cosubstituted by $\mathrm{Co}$ and $\mathrm{Ni}$ atoms, the volume fraction of LPSO phase increased further.

(2) After extrusion for $430^{\circ} \mathrm{C}, \alpha-\mathrm{Mg}$ and intermetallic compound particles broke up and distributed along the ED. LPSO phases bend in a certain degree and distribute along the $\mathrm{ED}$, providing excellent sites for the dynamic recrystallization nucleation, which made the difference of LPSO phase volume fraction and the degree of recrystallization, leading to different grain size of these four alloys. The grain size of MYZ, MYZC, MYZN, and MYZCN alloys was $2.8 \mu \mathrm{m}, 3.7 \mu \mathrm{m}, 2.6 \mu \mathrm{m}$, and $3.1 \mu \mathrm{m}$, respectively.

(3) The TYS of extruded MYZ, MYZC, MYZN, and MYZCN alloys were $315 \mathrm{MPa}, 245 \mathrm{MPa}, 340 \mathrm{MPa}$, and $345 \mathrm{MPa}$. Compared with grain size, recrystallization, texture, and other factors, the LPSO phase has a more obvious effect on the strength. The variation trend of its volume fraction is basically consistent with that of yield strength.

\section{Data Availability}

The data used to support the study cannot be shared.

\section{Conflicts of Interest}

The authors declare that they have no conflicts of interest.

\section{References}

[1] E. Dogan, I. Karaman, G. Ayoub, and G. Kridli, "Reduction in tension-compression asymmetry via grain refinement and texture design in Mg-3Al-1Zn sheets," Materials Science and Engineering: A, vol. 610, pp. 220-227, 2014.

[2] H. Huang, H. Kato, C. Chen, Z. Wang, and G. Yuan, "The effect of nanoquasicrystals on mechanical properties of asextruded Mg-Zn-Gd alloy," Materials Letters, vol. 79, pp. 281-283, 2012.

[3] Y. Kawamura, T. Kasahara, S. Izumi, and M. Yamasaki, “Stichwortverzeichnis," pp. 453-456, 2020.

[4] H. Liao, J. Kim, T. Liu et al., "Effects of Mn addition on the microstructures, mechanical properties and work-hardening of Mg-1Sn alloy," Materials Science and Engineering: A, vol. 754, pp. 778-785, 2019.

[5] X. Wu, F. Pan, R. Cheng, and S. Luo, "Effect of morphology of long period stacking ordered phase on mechanical properties 
of Mg-10Gd-1Zn-0.5Zr magnesium alloy," Materials Science and Engineering: A, vol. 726, pp. 64-68, 2018.

[6] J. F. Nie, Y. M. Zhu, and A. J. Morton, "On the structure, transformation and deformation of long-period stacking ordered phases in Mg-Y-Zn alloys," Metallurgical and Materials Transactions A, vol. 45, no. 8, pp. 3338-3348, 2014.

[7] Y. M. Zhu, A. J. Morton, and J. F. Nie, "The 18R and 14H longperiod stacking ordered structures in Mg-Y-Zn alloys," Acta Materialia, vol. 58, no. 8, pp. 2936-2947, 2010.

[8] Y. Kawamura, K. Hayashi, A. Inoue, and T. Masumoto, "Rapidly solidified powder metallurgy Mg97Zn1Y2Alloys with excellent tensile yield strength above $600 \mathrm{MPa}$," Materials Transactions, vol. 42, no. 7, pp. 1172-1176, 2001.

[9] L. Ye, Y. Liu, D. S. Zhao et al., "Effects of Sn on the microstructure and mechanical properties of a hot-extruded MgZn-Y-Sn alloy," Materials Science and Engineering: A, vol. 724, pp. 121-130, 2018.

[10] F. Qi, D. Zhang, X. Zhang, and X. Xu, "Effects of Mn addition and X," Materials Science and Engineering: A, vol. 593, pp. 70-78, 2014.

[11] F. Shi, C.-q. Wang, and Z.-m. Zhang, "Microstructures, corrosion and mechanical properties of as-cast $\mathrm{Mg}-\mathrm{Zn}-\mathrm{Y}$ (Gd) alloys," Transactions of Nonferrous Metals Society of China, vol. 25, no. 7, pp. 2172-2180, 2015.

[12] T. Itoi, K. Takahashi, H. Moriyama, and M. Hirohashi, "A high-strength Mg-Ni-Y alloy sheet with a long-period ordered phase prepared by hot-rolling," Scripta Materialia, vol. 59, no. 10, pp. 1155-1158, 2008.

[13] X. H. Shao, Z. Q. Yang, and X. L. Ma, "Strengthening and toughening mechanisms in $\mathrm{Mg}-\mathrm{Zn}-\mathrm{Y}$ alloy with a long period stacking ordered structure," Acta Materialia, vol. 58, no. 14, pp. 4760-4771, 2010.

[14] S. Gao, Y. Liu, D. Zhao, Y. Zhuang, S. Jia, and J. Wang, "Effect of different Co contents on the microstructure and tensile strength of Mg-Co-Y alloys," Materials Science and Engineering: A, vol. 750, pp. 91-97, 2019.

[15] Q. Q. Jin, X. H. Shao, X. B. Hu, Z. Z. Peng, and X. L. Ma, "New polytypes of LPSO structures in an Mg-Co-Y alloy," Philosophical Magazine, vol. 97, no. 1, pp. 1-16, 2017.

[16] J. Lyu, J. Kim, H. Liao et al., "Effect of substitution of $\mathrm{Zn}$ with $\mathrm{Ni}$ on microstructure evolution and mechanical properties of LPSO dominant Mg-Y-Zn alloys," Materials Science and Engineering: A, vol. 773, Article ID 138735, 2020.

[17] Q. A. Zhang, D. D. Liu, Q. Q. Wang et al., "Superior hydrogen storage kinetics of Mg12YNi alloy with a long-period stacking ordered phase," Scripta Materialia, vol. 65, no. 3, pp. 233-236, 2011.

[18] Z. Wang, Q. Luo, S. Chen, K.-C. Chou, and Q. Li, "Experimental investigation and thermodynamic calculation of the Mg-Ni-Y system (Y)," Journal of Alloys and Compounds, vol. 649, pp. 1306-1314, 2015.

[19] M. Jiang, S. Zhang, Y. Bi, H. Li, Y. Ren, and G. Qin, "Phase equilibria of the long-period stacking ordered phase in the Mg-Ni-Y system," Intermetallics, vol. 57, pp. 127-132, 2015.

[20] E. Abe, Y. Kawamura, K. Hayashi, and A. Inoue, "Long-period ordered structure in a high-strength nanocrystalline Mg-1 at\% Zn-2 at\% Y alloy studied by atomic-resolution Z-contrast STEM," Acta Materialia, vol. 50, no. 15, pp. 3845-3857, 2002.

[21] H. Liu, F. Xue, J. Bai, J. Zhou, and X. Liu, "Effect of substitution of 1 at $\% \mathrm{Ni}$ for $\mathrm{Zn}$ on the microstructure and mechanical properties of Mg94Y4Zn2 alloy," Materials Science and Engineering: A, vol. 585, pp. 387-395, 2013.

[22] H. Liu, F. Xue, J. Bai, and J. Zhou, "Microstructure and mechanical properties of a Mg94Y4Ni2 alloy with long period stacking ordered structure," Journal of Materials Engineering and Performance, vol. 22, no. 11, pp. 3500-3506, 2013.

[23] T. Itoi, T. Seimiya, Y. Kawamura, and M. Hirohashi, "Long period stacking structures observed in Mg97Zn1Y2 alloy," Scripta Materialia, vol. 51, no. 2, pp. 107-111, 2004.

[24] Y. M. Zhu, M. Weyland, A. J. Morton, K. Oh-ishi, K. Hono, and J. F. Nie, "The building block of long-period structures in Mg-RE-Zn alloys," Scripta Materialia, vol. 60, no. 11, pp. 980-983, 2009.

[25] H. Liu, H. Huang, J.-P. Sun et al., "Microstructure and mechanical properties of Mg-RE-TM cast alloys containing long period stacking ordered phases: a review," Acta Metallurgica Sinica, vol. 32, no. 3, pp. 269-285, 2019.

[26] Q.-Q. Jin and S.-B. Mi, "Intermetallic phases in Mg-Co-Y alloys," Journal of Alloys and Compounds, vol. 582, pp. 130134, 2014.

[27] C. Xu, M. Y. Zheng, S. W. Xu et al., "Microstructure and mechanical properties of rolled sheets of Mg-Gd-Y-Zn-Zr alloy: as-cast versus as-homogenized," Journal of Alloys and Compounds, vol. 528, pp. 40-44, 2012.

[28] B. Chen, D. L. Lin, X. Q. Zeng, and C. Lu, "Microstructure and mechanical properties of ultrafine grained Mg97Y2Zn1 alloy processed by equal channel angular pressing," Journal of Alloys and Compounds, vol. 440, no. 1-2, pp. 94-100, 2007.

[29] K. Hagihara, Z. Li, M. Yamasaki, Y. Kawamura, and T. Nakano, "Strengthening mechanisms acting in extruded Mg-based long-period stacking ordered (LPSO)-phase alloys," Acta Materialia, vol. 163, pp. 226-239, 2019.

[30] H. Liu, H. Huang, C. Wang et al., "Recent a-containing wrought magnesium alloys: relationships between processing, microstructure, and mechanical properties," JOM, vol. 71, no. 9, pp. 3314-3327, 2019. 